\title{
1. Publish or perish: Origin and perceived benefits
}

\subsection{THE NOTION OF PUBLISH OR PERISH}

'Publish or perish' (POP) is a phrase that describes the pressure put on academics to publish in scholarly journals rapidly and continually as a condition for employment (finding a job), promotion, and even maintaining one's job. In the Oxford Dictionary of Phrase and Fable, 'publish or perish' is used to refer to an attitude or practice existing within academic institutions, whereby researchers are put under pressure to produce journal publications in order to retain their positions or to be deemed successful. The POP issue is primarily relevant to those working in academic institutions (called academics, academic researchers, or just researchers). However, some of the aspects of POP discussed in this book are relevant to non-academic personnel who also seek publications because they are expected to publish, such as those working in medical laboratories, central banks and international organizations (UNCTAD, WHO, IMF, BIS, etc.).

De Rond and Millier (2005) suggest that "[t]here are few more familiar aphorisms in the academic community than "publish or perish", which is venerated by many and dreaded by more'. The phrase signifies a doctrine according to which the destiny of an academic depends exclusively on success in publishing scholarly work. The process involves a race against time that typically begins when an academic is hired and comes to an end when he or she is retired or dead. Recruitment, promotion and tenure are determined primarily by the publication record, as judged by quantity and quality (although it is not clear how quality is measured). As De Rond and Millier (2005, p. 322) put it, 'the publish or perish principle appears to have become the way of life in academia'. Indeed, the POP culture has been globalized as universities worldwide demand and measure performance in terms of publications.

Academics who do not comply with the POP stipulation perish, in the sense of not finding jobs or losing existing jobs. At best, the perish part is denial of promotion and the requirement of assuming a heavy teaching load while under the threat of termination. However, POP may mean different things, depending on the stage of academic career. Graduate 
students who do not produce publishable work find it hard to find jobs, which means that they perish by finding themselves with no place in the academic job market. For new academics, the perish part takes the form of failure to obtain tenure or go through probation. In North America, those employed on tenure track contracts are expected to publish a specific number of articles in top-ranked journals over a relatively short period of time. For academics to progress through their career, the rules of POP must be obeyed. For those who have made it through the tenure track and probation, 'perish' could mean denial of further promotion, the loss of research funding and even termination.

Elliott (2013) uses the expression 'currency for academic careers' to describe publications, arguing that 'they are probably the most important factor determining whether a young researcher gets a postdoctoral research position or lectureship... whether an assistant professor gets tenure and promotion and whether grants are won' (p. 625). For more senior academics, publications play an important role in promotion and in determining standing in the academic community. Senior academics may also be under pressure, from their PhD students and junior colleagues, to help them publish as much as possible.

Academia has become a POP world. In a survey conducted by Plume (2013), 81 per cent of the respondents agreed with the following statement: 'My career depends on a history of publishing research articles in peer reviewed journals'. Several reasons were put forward by the participants for agreeing with the statement: (1) 'At my institution, there are defined thresholds of publications for academic promotions at least during early career'; (2) 'Articles in peer-reviewed journals make the most important contribution to my career in terms of status, merit pay and marketability'; (3) 'If I publish well, I have more chance to get a better position and to obtain grants'; and (4) 'Because the primary role of my job is to produce research, which is of no use if it does not get into the public domain'.

POP may be advocated on the grounds that a good track record in publications brings attention to the authors and their institutions, which can facilitate continued funding and the progress of the authors themselves. Conversely, those who publish infrequently or focus on activities that do not result in publications (such as the vital activity of teaching undergraduate students) are likely to lose ground in competition for new jobs and promotions - they may even lose their existing jobs. We will find out that the perceived benefits of POP pale into insignificance compared to the adverse consequences of guiding academia by the rules of this doctrine.

According to Plume and Van Weijen (2014), the POP phenomenon has become a focus of academic research itself, as a search for the phrase in Scopus retrieved 305 documents published on the topic since 1962. On 
average, more than 20 articles per year were published on the topic during the period 2009-13. These studies deal mainly with the consequences of POP, which will be described in detail in Chapters 2-4. One consequence of the pressure put on academics to publish is that poor work is invariably submitted to academic journals, some of which appears in print although it lacks substance. While publication rates are at an all-time high as a result of POP, this growth has not been caused by improvement in productivity but rather by changes in publication patterns. The growth of research output has not been accompanied by improvement in quality as perceived by academics, let alone quality as measured by impact on the society.

The phenomenon of POP has also been dealt with in several articles published in prominent North American newspapers. According to Spooner (2014) these articles correctly attribute changes in academia to 'the publish-or-perish culture that overwhelmingly imbues our universities'. For example, Lawrence Martin argues in an article in the Globe and Mail that '[a]cademia has been overtaken by specialists who are absorbed in their own little world with its imperative to publish' (Martin, 2013). In the New York Times, Nicholas Kristof (2014) contends that '[i]f the sine qua non for academic success is peer-reviewed publications, then academics who "waste their time" writing for the masses will be penalized'. Writing in the Ottawa Citizen, Tom Spears (2014) brings attention to 'some of these, nicknamed predatory journals, [which] offer fast, cut-rate service to young researchers under pressure to publish'. The growth of predatory journals will be dealt with in Chapter 3.

The POP culture has led to a relentless quest for publications - the sole objective being CV building rather than the advancement of human knowledge. Elmer (1982, p. 313) tells a story of how things were in 1958, before POP took hold of academia, and the present time in which POP dictates the destiny of academics. He writes:

In 1958, when James D. Watson worked his way up to the rank of associate professor at Harvard, the young biochemist had on his curriculum vitae 18 papers. One of them, published 5 years earlier, described the structure of deoxyribonucleic acid. Today, the bibliography of a candidate facing a similar climb often lists 50 or even 100 papers. As the comparison suggests, paper inflation has become a fact of academic life during the past two decades.

Colquhoun in The Guardian (2011) highlights the phenomenon of paper inflation under POP, arguing that "[t]o have "written" 800 papers is regarded as something to boast about rather than being rather shameful' and that '[u]niversity PR [public relations] departments encourage exaggerated claims, and hard-pressed authors go along with them'. It is not surprising therefore that Colquhoun (2011) describes the status quo 
in academia as 'this sad situation', blaming it on 'the people who have imposed a publish-or-perish culture, namely research funders and senior people in universities'.

\subsection{THE ORIGIN OF POP}

There is no consensus view on who actually coined the term 'publish or perish'. Garfield (1996) suggests that it is difficult to trace the origin of what he calls the 'ubiquitous expression publish or perish'. By conducting a literature search, he revealed that none of the authors writing about POP had cited a source for this 'common expression'. He also searched dictionaries, both in print and online, but that search produced nothing.

According to Garfield (1996), the expression appeared for the first time in an academic context in Wilson's (1942) book, The Academic Man: A Study in the Sociology of a Profession. In a chapter on prestige and the research function, Wilson referred to the 'prevailing pragmatism forced upon the academic group', describing it as being 'that one must write something and get it into print', hence: 'Situational imperatives dictate a "publish or perish" credo within the ranks' (p. 197). However, Garfield (1996) argues that it is not clear whether Wilson cited someone who coined the term or he coined it himself. Hence there is no agreement on whether or not Logan Wilson, a former President of the University of Texas, was the first person to use the phrase 'publish or perish' in print - that is, it is not certain whether he created the phrase or got it from a source. Since Wilson is dead, the true origins of POP retain a certain element of mystery.

There are, however, other views on the origin of POP. In a non-academic context, the phrase appears in Coolidge and Lord (1932), where it is stated that 'the Council must publish or perish' (p. 308). In 1938 the phrase appeared in Volume 24 of the Association of American Colleges Bulletin, where reference is made to 'read or barbarise' (p. 465) and also to 'publish or perish'. Sojka and Mayland (1993, p. 202) attribute the expression to Kimball Atwood, a geneticist at Columbia University. They write:

'Publish or Perish' is a phrase that may have originated with Kimball C. Atwood, then of Columbia University, sometime during or shortly before 1950. It is the scientists' equivalent of 'The buck stops here; Cherche' la femme [sic]; and Live long and prosper' all rolled into one maxim. And yet the story of its utterance is a lesson unto itself. For today its origin with Atwood can only be documented anecdotally. Atwood never published the phrase, and as the story goes, had only to wait a month before he heard it delivered in an address by a visiting lecturer, who afterward told Atwood he heard the phrase from a participant in Atwood's originating conversation. 
Yet another view is presented by Shapiro (1998) who asked John Simpson, the editor-in-chief of the Oxford English Dictionary (OED), about the earliest use of the phrase in the OED. The response that Shapiro got was that the earliest citation could be traced to a letter written by Marshall McLuhan to Ezra Pound on 22 June 1951, which said the following:

The beaneries [Pound's term for universities] are on their knees to these gents [foundation administrators]. They regard them as Santa Claus. They will do 'research' on anything that Santa Claus approves. They will think his thoughts as long as he will pay the bill for getting them before the public signed by the professorry-rat. 'Publish or Perish' is the beanery motto.

Irrespective of who coined the expression or who put it in writing first, POP is the doctrine according to which contemporary academia is run. This is a not a non-trivial matter because the doctrine has changed academia in a substantial manner. Most academics seem to believe that academia has changed for the worse as a result of the POP culture, although a view that is expressed by people from within and outside the profession suggests that it is an excuse for academics to complain. According to Plume and Van Weijen (2014), 'it seems clear that researchers suffer from this phenomenon on an increasing scale'.

\subsection{PERCEIVED BENEFITS}

One perceived benefit of the POP model is that some pressure to produce research is necessary to motivate academics early in their careers to focus on research advancement and learn to balance research activity with other responsibilities. Another perceived advantage is identified by Van Dalen and Henkens (2012) who argue that '[t]he publish-or-perish model and our reliance on publication metrics, is not altogether bad - as it helps to identify and reward scientists based on merit and not on favoritism and nepotism - only that it comes with consequences for the role of science in society'. Other supportive statements come from Cohen (2010) who argues that 'publishing in elite journals is an unavoidable part of university life'; Meltzoff (2005) who suggests that 'publication means bringing written materials to the public'; and Scanes (2007) who contends that 'graduates and academic scholars have an obligation to publish a record of publication' and that 'dissemination is the first step in the career ladder'. Sojka and Mayland (1993, p. 202) go even further by arguing for the importance of publications in academia. This is what they have to say:

Publication documents the precedence of ideas. It documents the stewardship of research funds. It documents the productivity of scientists, justifies our 
salaries and our reputations, and allows the cultivation of our egos. But most importantly, it liberates information and knowledge from the imprisonment of chaos and file cabinets to the free access of other scientists and for the betterment of mankind. The publication ethic was being evoked as early as the mid18 th century by Benjamin Franklin, who exhorted scientists simply 'to study, to finish, to publish'.

Why is it that publication is given more importance than other academic duties and do publications represent the only measure of output or performance? After all, the ability to publish a paper in general or in a particular journal may be beyond the control of the researcher. Whether a paper gets accepted for publication is only partly determined by the quality of the paper and the soundness of the research. Other factors that determine the fate of a submitted paper, and hence a researcher's career opportunities, include journal policies, the referee's mood, the papers submitted by other researchers, and so on. I have always said that, if a paper is well written and presented and it is free of fundamental errors, the acceptance or rejection of the paper is a stochastic process. In a sense, then, publication as a measure of performance may be indicative of 'criterion contamination'. Sojka and Mayland (1993) get it wrong on three fronts: (1) no mention of the role of academics as teachers and educators, which should also justify salaries; (2) there is no such thing as a free access to published work; and (3) most published research these days has nothing to do with the 'betterment of mankind'.

POP has caused inflation of publications over the past few decades. Things have changed from publishing when there was something important to publish to the status quo of publishing because we have to, irrespective of whether or not what we want to publish is worthy of publishing. As a result, we can readily witness a destructive race to the bottom. In an interview on Indecision Blog, Dick Thaler (a renowned economist) suggested that the research that led to Kahneman's (and Tversky's) Nobel Prize would not be adequate to obtain tenure in many places these days although it is more deserving of tenure than a long list of publications each of which contributes little or nothing (Halonen, 2013).

Even if the perceived benefits of POP are real, they are overwhelmed by the realized and tangible adverse consequences of working under the conditions dictated by POP. The benefits are illusory, as academics are forced to publish anything rather than caring about the advancement of human knowledge, which cannot materialize under pressure. The POP culture does not teach academics how to balance research with other responsibilities - rather it encourages them to ignore other responsibilities (including teaching) and concentrate on research that is more often than not of interest to the author only. As a part of a survey conducted 
by Mason, Steagall and Fabritius (1992), a disenchanted economist commented on what is published in economics journals by declaring that he found 'most of the contents to be of possible interest only to the authors'. He adds the following:

I suspect that the average readers-per-article is less than one, even among academics. The growth of journal publication in all fields of science is ludicrously disproportionate to the advances of knowledge. I attribute this to the replacement of the search for truth by frenzied resume building. It has occurred to me that vast savings of money, timber and library shelf-space would be accomplished by replacing journals with tables of contents. Anyone wanting to read a piece could send for a copy. Better yet, more savings would be accomplished if the articles were written only after such a request.

This disenchanted economist describes succinctly the kind of research encouraged by the POP culture.

The perceived benefits of rewarding scientists on the basis of merit require the definition of merit. Under the POP model, merit is measured by the quantity and quality of publications, but how do we measure the quality of publication? For example, is there more merit for one of ten authors of a paper appearing in a top journal (say ranked 5) than for a single author in a journal that is ranked 20? We will see that journal ranking is a hazardous business and that not every paper published in a top journal is a high-quality paper. When POP is the rule of the land, there is no merit in non-research activities (such as teaching and community service), no merit in non-article publications, and no merit in good research that does not get published in a top journal very quickly.

Contrary to the argument of Van Dalen and Henkens (2012), the POP culture discourages research that is beneficial to the society as a whole. Let us for the sake of argument assume that the advancement of science and human knowledge in general is broadly represented by the mission and objectives of the American Association for the Advancement of Science (AAAS). The mission is to 'advance science, engineering, and innovation throughout the world for the benefit of all people'. The broad goals associated with the mission are: (1) enhancing communication among scientists, engineers and the public; (2) promoting and defending the integrity of science and its use; (3) providing a voice for science on societal issues; (4) promoting the responsible use of science in public policy; (5) strengthening and diversifying the science and technology workforce; (6) fostering education in science and technology for everyone; and (7) increasing public engagement with science and technology. The culture of publish or perish is certainly not conducive to the achievement of the AAAS objectives. Under POP, the public, societal issues, public policy, the workforce and 
everyone else are irrelevant. Academics conduct research not to benefit the society but to get their names in journals, preferably top journals - and no one can blame them for that as they have to follow the rules of the game or else perish. Under POP, the objectives change from advancing society to advancing (or preserving) oneself by building an 'impressive' CV containing 250 publications.

Even POP enthusiasts, such as Van Dalen and Henkens (2012), admit that POP has drawbacks. This is how they interpret their results:

The results presented in this article show that the publish-or-perish culture can have both beneficial and detrimental effects. . . A consensus can be detected on the benefits of publications, as they improve the upward mobility of scientists. However, the detrimental effects revealed are the widening gap between science and policy, and especially for those scholars working outside the United States the incentive to publish in peer-reviewed journals is perceived to discourage the production of local knowledge.

Hence, Van Dalen and Henkens (2012) identify two serious consequences of POP: (1) publications become increasingly irrelevant to policy (and divorced from reality); and (2) bias against research that produces national benefits, which is particularly alarming for developing countries.

The rules of POP dictate that academics report some publications at the end of the year to 'meet expectations' and satisfy the objectives stated in the 'work plan'. What academic departments strive for is to provide a list at the end of the year containing a large number of publications, with some appearing in top journals. However, publishing a paper in a top journal does not guarantee any impact on the profession or, more importantly, society at large. As far as society is concerned, publishing in a triple A journal or a triple $\mathrm{Z}$ journal makes no difference whatsoever. But even for the academic community, while it is often claimed that what matters is the quality of research, quality under publish or perish is judged in terms of the journals where publications appear, not in terms of impact. The issue of journal quality and classification, as well as the hazard of journal ranking, will be considered in Chapters 5 and 6 .

The argument that research is conducive to good teaching is not necessarily valid. Universities are supposed to be teaching institutions, the venues for acquiring specialized knowledge as opposed to the general knowledge acquired in primary and secondary school. Universities produce doctors, engineers and economists by passing on knowledge through teaching. Yes, it is true that the knowledge passed on by a professor to his or her students may benefit from his or her research, but that ceases to be the case under POP where research and publications become the end rather than a means to an end. Under POP the last thing a professor wants is a 
student knocking on her door to ask a question. Research-active professors strive to avoid teaching, even by buying out teaching time financed by grant money that is supposed to be used to finance research. Under POP, research and teaching cease to be complementary and become two incompatible functions competing for limited resources.

\subsection{THE RISE AND RISE OF POP}

Once upon a time, when governments viewed higher education as an investment rather than a cost, universities were well funded. At that time, academics ran the show and a vice-chancellor was typically a brilliant scholar who got paid a salary loading of no more than 10 per cent of the professorial salary. The standard of graduates was extremely high and the academic staff enjoyed job satisfaction. With the passage of time, governments decided that it was wise to spend taxpayers' money on wars instead of higher education, so they started starving universities of funds, encouraging them to operate like businesses - and so they have done. Vicechancellors became CEOs with seven-figure salaries and a big entourage of suit-and-tie bureaucrats with fancy job titles such as assistant deputy vice-chancellor for sustainability, deputy pro-vice-chancellor for design and innovation, pro-vice-chancellor for engagement activities, associate pro-vice-chancellor for academic partnerships, deputy vice-chancellor for engagement and vocational education, pro-vice-chancellor for design and social context, and assistant deputy pro-vice-chancellor for the campaign against Donald Trump (I made up the last one, but it is no more ridiculous than the real ones). On a more junior level of the bureaucracy, there has been a significant increase in the number of employees called 'senior managers' - as a matter of fact every administrative staff member has become senior something. Schools and departments have school managers, who typically think they are more important than professors. These bureaucrats are called 'professional' staff, which means that academics are 'unprofessional'.

Ryan (2005) argues that the changes enforced by the Thatcher government and reinforced by successive governments, both in Britain and in other parts of the English-speaking world, led to a development whereby increasingly scarce funds are absorbed by a 'growing managerialist/administrative group'. As a result, he argues, 'The growth of this group has been remarkable and today it is not uncommon that academic staff form less than 50\% of the total employed by a university' (p. 658). Universities started advertising for students to the extent that one university advertised that anyone who got a new student to enrol would be rewarded with a fully paid holiday in 
Bali. Needless to say, standards deteriorated as courses were watered down and academics were told to treat students like customers (and, as we know, the customer is always right). This has been a characteristic of what Ryan (2005) calls the 'new consumerist mass system that prevails today' (p. 657). Al-Nakeeb (2016, p. 99) describes the situation in Britain as follows:

In Britain too, under the present conservative government, public universities, which used to be free before the Thatcher-Reagan counter-revolution, are now charging students nine thousand pounds a year. Education no longer caters for merit but money. Learning is rationed so the have-nots remain ignorant, which expedites the perpetuation of plutocracy and the deterioration of democracy. It also means that a major part of the Anglo-Saxon world is steadily falling behind countries with relatively generous education budgets like China, India, Japan, and Russia. (Original emphasis)

Following the Reagan-Thatcher 'reform' of everything except the war machine, governments started funding universities on a model that depends on the number of students and research performance. To boost the first metric (number of students), universities started to water down entry requirements. The second metric, research performance, led to the rise of the POP mentality. Universities then started seeking research grants from both the government and the private sector, thus boosting the POP culture, since grant applications do not succeed without impressive publication lists (unless of course the applicant knows members of the panel). Big bureaucracies evolved to implement the new business model in which academics are looked upon (by senior suit-and-tie bureaucrats) as being 'hopeless'. Still, these hopeless people are expected to spend a big portion of their time filling application forms to attract external research funds, which is taxed by the centre to pay the bonuses of those who think that academics are hopeless. This is a far cry from days gone by when it was expected that someone with a $\mathrm{PhD}$ would obtain a permanent position in which teaching was the primary responsibility.

According to the discussion so far, the rise of POP can be attributed to changes in university funding by the government, which depends largely on research output. Indicative of this tendency is the distinction between the best and the rest - that is, between elite universities that have strong research records and the rest of universities that are not blessed by strong research records. The quality of teaching and student satisfaction has no place in the equation. Within universities, bureaucratic apparatuses evolved to manage research where bureaucrats are in charge. For example, scarce time is typically wasted on research meetings that involve the discussion of 'vital issues', as in this meeting called for via the following email sent by a research administrator: 
Our Research Centres and Research Groups. . connect researchers with a shared purpose, support research leadership and provide recognition for areas of research strength. The Research Office invites researchers and research administrators to a workshop to discuss how Research Centres and Research Groups can work better. . These discussions will inform the Research Centres and Research Groups policy rules and processes. We hope to agree on appropriate establishment criteria, how best to manage and review Research Centres and Research Groups, as well as other key issues.

Those with sharp eyes will readily observe that the word 'research' appears 12 times in this email. At a time when researchers are expected to produce publications, more time is spent attending meetings about research than the time allocated to doing the research itself. It is a tragic situation caused by governments that have the wrong ordering of priorities as unnecessary wars come first. What is more tragic is that these changes in university funding are called 'reform' - so beware of reform.

While the majority of academics accept this explanation for the rise of POP, others present alternative explanations. One explanation, which provides justification for the status quo, is that POP is good because it encourages the conduct of research. De Rond and Millier (2005) explain how the POP culture started in US business schools in terms of the belief that research in business is important. In the mid-1950s, the Ford Foundation (Gordon and Howell, 1959) and the Carnegie Corporation (Pierson, 1959) commissioned independent inquiries into the status of business education in the USA. The reports emanating from the two studies were published in 1959, both criticizing the status quo with respect to research and teaching, with the implicit assumption that good teaching goes hand in hand with good research. In particular, the two studies found that research was based on 'feeble empirical evidence and insufficient analytical rigor and depth of penetration'. The studies also noted the 'conspicuous absence of high-quality journals'. In reaction to these findings, business schools began to stress the development of a stronger research culture. It was then that research was transformed from a peripheral activity to 'the decisive criterion of the academic enterprise', as it was given equal or greater emphasis than teaching (Porter and McKibbin, 1988).

This change was felt in Europe. In the United Kingdom, the Franks Commission (1966) released a report that recommended the creation of two national business schools (in London and Manchester) to enhance the quality and provision of management education. In France, the response took the form of establishing a foundation to foster management education. In the particular case of management research, the POP culture has encouraged the proliferation of nonsense - that is, research (if it may be called so) dealing with trivial issues such as the effect of the colour of the 
annual report on corporate performance and how to convince surfers to eat more hot dogs. This kind of nonsense is hardly conducive to good teaching. However, I must say that some research in management is highly useful, but when everyone in management is forced to publish, we get nonsense (which is true for every other discipline).

Another explanation for the rise of POP can be found on the Neuroskeptic blog (2013) where it is argued that perishing is not necessarily linked to publishing, but rather that the association between the two is a coincidence. Perishing, according to this view, is related to the survival of the fittest. In today's academia, there are more people at the bottom $(\mathrm{PhD}$ students) than there is room at the top (professorships). At every step up on the career ladder, less posts are available, which means that not all of those entering academia will make it to the top and that some of them (perhaps the majority) will perish somehow. Perishing is therefore attributed to competition for jobs and advancement - it is 'an inevitable consequence of the demographics'. According to this view, perishing is linked to publishing only by accident, just because it happened that academics are assessed mostly by their publications, which means that publishing is the means whereby perishing can be avoided. If this argument is valid, the appropriate course of action is not to 'reform' the publication process or to evaluate academics by alternative criteria.

The rise of the POP culture cannot be attributed solely to governments that look at higher education as a cost not an investment or those believing that it is not their job to fund education. Tam (2007) quotes a former president of York University, Canada, Harry Arthurs, as saying that he blamed the culture shift on the private sector's eagerness to commercialize research and that universities and governments gave in to pressure to show a return on public investment. Arthurs actually condemned academics for being 'not only complicit, but sometimes proactive in these developments'. Colpaert (2012) argues that it is 'really a shame for institutions that call themselves universities' to yield to this kind of pressure and evaluate their academic staff as suggested by governments. Kostoulas (2014) contends that 'by rewarding articles that offer the appearance of legitimacy, but do not necessarily contain significant discoveries, academic journals perpetuate a "public-or-perish" culture that incentivizes researchers to compromise academic rigor and churn out articles at an unrealistic pace'. And by measuring academic success through journal publications, universities ultimately foster this same culture on their campuses. 


\subsection{POP AS A CONSEQUENCE OF GLOBALIZATION AND NEOLIBERALISM}

It has been suggested by some observers that globalization has led to the 'McDonaldization' of universities (Altbach, 2004). Lo (2011) argues that global scholarship is predominately defined by the West (read the US 'fan club'). As Deem, Mok and Lucas (2008) point out, the quest for best practices and more advanced systems leads to 'policy copying' through which non-Western (that is, non-Anglo-American) higher education systems have been strongly influenced by the Anglo-American standards and ideologies. The globalization of higher education can be interpreted as a form of neocolonialism that maintains the patterns of dependency and reinforces the superiority of Anglo-American scholarship. Colpaert (2012) outlines major changes that have transformed the academic landscape, including the impact of neoliberal ideology on the evaluation of academic quality. This ideology has led to a policy whereby universities are held accountable for the scholarly output they produce, as measured by the numbers of publications and citations. Altbach $(2015$, p. 2) describes the changing environment in universities as follows:

Universities worldwide are becoming marketized, privatized, differentiated, and otherwise changed to meet the demands of an academic environment that stresses accountability and mass access. Higher education is increasingly seen as a 'private good' - a commodity that should be subject to the logic of the market. These changes have had a profoundly negative impact on the academic profession - the heart of any academic enterprise. Working conditions and career paths for the academic profession are deteriorating.

The spread of POP is like the spread of McDonald's (and the junk-food industry in general), which came with globalization. Neoliberal thinking dictates that whatever is done in America is right for the rest of the world. Privatization is good under any conditions, so countries worldwide started to privatize public assets. Subsidies are bad because they undermine economic efficiency, so countries started removing subsidies, irrespective of the pain inflicted on the poor by doing just that. Like privatization, POP must be good because it is a principle based on the free-market doctrine that leads to efficiency and hence welfare. So, countries started to adopt POP as the model used to manage universities. This has happened even in countries that do not think that education is a cost, such as China. Even countries where funding for higher education has not been cut, the allocation of these funds is determined by the rules of POP.

Djuric (2015) discusses the academic setting in Serbia after 2007 when state universities began requiring publication in journals having Thomson 
Reuters (TR) Journal Impact Factors for completion of a $\mathrm{PhD}$ or promotion. In the rest of the world, the POP culture thrived even in publicly funded universities because publications are required for accreditation (by American bodies). In China the phenomenon has taken hold of universities - Tian, $\mathrm{Su}$ and $\mathrm{Ru}$ (2016) argue that China has followed the Anglo-American model by recognizing research productivity as conducive to economic competitiveness. The Chinese government has decided to boost research expenditure, leading to competition for government funding amongst Chinese universities. As a result, Chinese universities are putting great pressure on their staff to publish in journals appearing in the Science Citation Index (SCI) and Social Science Citation Index (SSCI). Tian et al. conclude as follows $(2016$, p. 1):

A so-called 'publish-or-perish' academic culture, as a result of the Chinese universities' introduction of various evaluation and incentive policies, is now emerging on campuses. The culture particularly affects junior faculty. The number of papers these young scholars publish often determines their career path.

One consequence of the spread of the POP culture to Chinese universities is that Chinese academics have become reluctant to spend time on non-research academic activities, including teaching and training. Tian et al. (2016) also report that considerable time is devoted to writing, which results in fatigue and negatively affects family relations. Participants in the survey conducted by Tian et al. admitted that they had to rush to publish, and therefore were less likely to produce papers of better quality or those with novel discoveries.

There is no doubt that academia has endured significant changes as a result of the dominance of the neoliberal market ideology. At one time academics enjoyed a high degree of autonomy as well as fairly secure academic freedom. The few research 'stars' were rewarded mainly with high status rather than large salaries, and most were teachers who did little research. Altbach (2015) argues that these changes are not observed in the USA only - rather, deteriorating conditions for academics is a worldwide phenomenon, thanks mainly to globalization. This is what he says about other countries (p. 3):

In other countries, the situation is similarly grim. The traditional employment security of the academic profession is being weakened by moving academics from the civil service. In Britain, tenure was abolished as part of a major university reform aimed at making the entire academic system more competitive. In Germany, most new academic appointments do not permit promotion, forcing many academics to compete for new positions at other universities. In Central Europe and the countries of the former Soviet Union, the traditional academic 
profession has been greatly weakened by changes in working conditions, deteriorating salaries, and loss of status. It is common in developing countries for academic salaries to be so poor that even full-time professors must hold more than one job. In Latin America, traditional reliance on part-time teachers has prevented the emergence of an effective professoriate.

A profession that thrived on autonomy and a certain detachment from direct competition is now exposed to the tyranny of the market all over the globe. It is indeed a tragic situation.

\subsection{POP, PAP, PBNP, PWOP, BMOP AND PAFOP}

POP implies that if an academic publishes well, he or she will have a happy working life without the fear of perishing. However, this is not always the case, as publishing may be a necessary but not a sufficient condition for not perishing. In this case POP becomes PAP (publish and perish) or, what Molinié and Bodenhausen (2010) call 'publish but nevertheless perish' (PBNP).

In 2016 a member of the academic staff of a university published 19 papers, two book chapters and a book, while obtaining two research grants and producing five successful $\mathrm{PhD}$ completions. Even by the rules of POP, one would tend to think that this particular academic would be left in peace and rewarded with less teaching in 2017. But that was not to be the case, as he was hit with a teaching load involving seven different subjects in the second semester of 2017 (this is a true story). It remains to be said that in this particular institution, the expected performance of a professor over three years is nine papers of acceptable quality, the supervision of an average of seven research students, the production of four successful completions (masters or PhDs) and obtaining external research grants of $\$ 300000-500000$. And yes, these expectations apply to someone who is required to teach seven different subjects in one semester and to those who are about to retire (no reprieve whatsoever).

I should not forget to say that high teaching scores must be achieved as determined by the 'customers' through the quality of teaching survey. An academic must not only publish but also strive to get a high GTS (Good Teaching Scale) score and OSI (Overall Satisfaction Index). A good publisher may still perish if he or she does not do well in terms of student evaluation scores or fails to obtain research grants.

Various situations arise leading to the emergence of new POP-related concepts. For example, the classification of academic staff into the 'best' and the 'rest' gives rise to the concept of publish while others perish (PWOP). Under POP, the best are the star publishers, even though the 
contribution of their research to human welfare is zero, whereas the rest are those who do not fall under the first category. The best get research money and little teaching whereas the rest are deprived from resources and recognition while they have to do the unimportant job of teaching. So, the best publish while the rest perish. And because academics are expected to bring in external research funding, someone who fails to do so may perish. This is a situation of BMOP (bring money or perish). In general, however, attracting external research funding is dependent on publishing. Therefore, the situation is PAFOP - that is, publish and flourish or perish.

\subsection{THE ADVERSE CONSEQUENCES OF POP: A PREVIEW}

While it is easy to dismiss POP as an excuse for academics to complain about working conditions, the imposition of pressure to publish or perish (or publish and still perish) has adverse consequences for the individuals concerned, academia and the progress of human knowledge. In the following three chapters we consider these consequences in detail. In Chapter 2, we examine the effect on the quality of research and dissemination of knowledge. In Chapter 3, we deal with the growth of the journal industry and the changing authorship pattern, with the rise of the fractional author and the demise of the solo author. In Chapter 4, we will see how the POP culture has led to various forms of research misconduct, including plagiarism, violation of generally accepted research practices, falsification and fabrication of data, and others.

This chapter comes to an end with a sombre note on the adverse effects on the health and well-being of academics who are put under pressure to publish while under constant threat of perishing one way or another. Kinman and Wray (2013) used health and safety executive measures, assessed against a large sample of over 14000 university employees, to reveal growing stress levels among academics prompted by heavy workloads, a long-hours culture and conflicting management demands. They found that academics experience higher stress than those in the wider population. The environment created by POP is punitive, resulting in a negative influence on life balance, health and well-being. Under a POP environment, women are likely to suffer more than men, given the busy life of women attempting to balance home and career.

Under publish or perish it is a never-ending struggle to come up with a list of publications at the end of the year in order not to perish. One brilliant economist worked so hard for 40 years and achieved everything that any academic economist wishes. Towards the end of his career, he wanted 
to wind down, so he moved to another university, thinking that he would spend the three years before retirement playing golf and mentoring colleagues and graduate students. But that was not to be, as he was told that he had to produce $\mathrm{x}$ numbers of papers in designated journals every year. This story is not unique to this particular economist but rather a very common story in academia. I am not sure if that particular economist is still in the same place, but I very much doubt that. It is this kind of environment that has led to the early and premature retirement of brilliant academics who would otherwise have contributed significantly by mentoring junior staff. This is also the same environment that has led to multiple shootings at Concordia University in 1992 when a professor shot and killed four professors (Arthurs, Blais and Thompson, 1994). Yes, POP may drive academics to the brink of insanity. 